\title{
Activation by light irradiation of oxidants electrochemically generated during Rhodamine B elimination
}

\author{
Danyelle Medeiros de Araújo ${ }^{1}$, Salvador Cotillas ${ }^{2}$, Cristina Sáez ${ }^{2}$, Pablo Cañizares ${ }^{2}$, \\ Carlos Alberto Martínez-Huitle ${ }^{1, *}$, Manuel Andrés Rodrigo ${ }^{2}$ \\ ${ }^{1}$ Federal University of Rio Grande do Norte, Institute of Chemistry, Lagoa Nova CEP \\ 59078-970 - Natal, RN, Brazil \\ ${ }^{2}$ Department of Chemical Engineering, Universidad de Castilla-La Mancha, Campus \\ Universitario s/n, 13071 Ciudad Real, Spain
}

\begin{abstract}
In this work, the role of chloro-species generated during the electrolysis of Rhodamine B $(\mathrm{RhB})$ solutions containing chloride and perchlorate salts as supporting electrolytes was studied. Likewise, the effect of light irradiation in the activation of the oxidants is also evaluated. To do this, essays of electrolysis, photoelectrolysis and chemical oxidation in presence of light with the oxidant generated electrochemically were carried out. Results showed that RhB was effectively oxidized by electro-irradiated techniques. Color removal is faster than chemical oxygen demand (COD) and total organic carbon (TOC) removal, due to the rapid attack of chromophore group of the molecule. In general, light irradiation has a positive effect during the electrolysis of $\mathrm{RhB}$ at high current densities. In chloride media, light irradiation seems to favor the decomposition of hypochlorite produced. Effect of light irradiation is explained in terms of the activation of oxidants in the bulk of the electrolytic treatment by production of highly efficient radicals. Results of chemical oxidation essays may indicate that UV light irradiation has not a clear catalytic influence out of an electrolytic environment. The findings presented in this communication are described and discussed in the light of the existing literature.
\end{abstract}

Keywords: Electrolysis, photoelectrolysis, chloride, Rhodamine B, diamond electrode. 


\section{Introduction}

In the recent years, the electrochemical treatment of dyes has demanded a special attention, focused mainly on the comparison of different anode materials, for example: $\mathrm{Pt}, \mathrm{PbO}_{2}, \mathrm{Ti} / \mathrm{Pt}, \mathrm{Ti} / \mathrm{Ru}_{0.3} \mathrm{Ti}_{0.7} \mathrm{O}_{2}$ and $\mathrm{BDD}$ anodes [1-4] or combination of different electrochemical technologies to remove dyes [1, 5-11] (anodic oxidation with other processes such as oxidants production, ultraviolet light (UV) irradiation, ultrasound (US) irradiation, electro-Fenton (EF), photoelectro-Fenton (PEF) and so on).

The electrochemical treatment by direct or indirect approaches [10], is based on the elimination of pollutants directly on the anode surface or/and, via production of ${ }^{\bullet} \mathrm{OH}[9$ 16] or additional oxidants [17-24], such as chlorine, (per)bromate, persulfate, ozone, hydrogen peroxide, percarbonate, and others, directly on-site using only water, salt, and electrical energy.

Nevertheless, the reactivity of many of the raw oxidants produced in electrochemical oxidation (EO) with organics is not very high and some sort of activation is often required to obtain a clear improvement of the process [10]. The formation of these highly reactive species (activated oxidants) from the oxidants contained in the wastewater is possible by three different modes [10]: (i) chemical activation, (ii) activation by light irradiation and (iii) activation by ultrasound (US) irradiation.

In the first case, it involves the combination of the oxidant produced electrochemically with another species (not necessary an oxidant), which leads to the production of a third, very reactive species. This is the case of the well-known Fenton processes [9]. UV light irradiation promotes the formation of highly active species [25]. This irradiation can be applied naturally (solar driven) or artificially (using UV lamps). Then, the photoactivation (or light-assisted decomposition) of electrochemically generate reactive 
species, such as $\mathrm{H}_{2} \mathrm{O}_{2}$ or $\mathrm{O}_{3}$, is attained [26-29]. Finally, US irradiation consists in the promotion of ultrasonic cavitation behavior [30]. This phenomenon takes place in a very short moment and space, increasing temperature and pressure [31]. After that, it can produce significant changes in chemical composition of the hot spot, and consequently promote the formation of new radical species and components, and so, it can increase the reactivity of the system [32].

Therefore, the aim of this work is to study the light irradiation activation of oxidants electrochemically generated at $\mathrm{BDD}$ anode when $\mathrm{NaCl}$ or $\mathrm{HClO}_{4}$ are used as supporting electrolytes. Treatment of synthetic solutions containing $\mathrm{RhB}$ was performed in order to establish the mechanisms involved and their effect on the efficiency. It is important to mention that, RhB is widely used in textiles, leathers and food stuffs with high water solubility [32, 33], and for this reason, it was chosen as model organic pollutant.

\section{Material and Methods}

\subsection{Chemicals}

The chemical reagents used in this study were of high purity. RhB (98\%) was supplied by Aldrich. Solution of $7.04 \times 10^{-3} \mathrm{M} \mathrm{NaCl}$ or $7.04 \times 10^{-3} \mathrm{M} \mathrm{HClO}_{4}$ were prepared and after that, these electrolytes were used for preparing a solution of $\mathrm{RhB}$ with concentration of $2.09 \times 10^{-4} \mathrm{M}$, for each experiment. All aqueous solutions were prepared using Milli-Q water.

\subsection{Analytical procedures}

Color removal was monitored by UV-visible technique using a UV-1603 spectrophotometer Model Shimadzu, at a wavelength of $550 \mathrm{~nm}$. Chemical oxygen demand (COD) was performed by using pre-dosage vials with $2 \mathrm{~mL}$ of sample. For the 
analysis of total organic carbon (TOC), it was necessary a minimum volume of $10 \mathrm{~mL}$ of each one of the samples to be analyzed. These analyzes were carried out in a TOC analyzer Multi N/C and the results obtained through the Analytikjena program. RhB samples before and after the treatments were collected and transferred to vials own high-resolution liquid chromatography (HPLC), injecting $50 \mu \mathrm{L}$ of each sample for analysis in Agilent 1100 HPLC (flow of $0.200 \mathrm{~mL} / \mathrm{min}$ ). Two columns were used for the analysis of intermediates generated during degradation of RhB. The mobile phases used for analyzing aromatics and aliphatic acids by HPLC technique were $0.9 \mathrm{ml}$ of $98 \%$ formic acid in $1 \mathrm{dm}^{3}$ of water and a mixture of acetonitrile and water (1:1), respectively.

\subsection{Bulk electrolysis}

Electro-oxidation experiments were carried out in a flow electrochemical cell (undivided) with a BDD disc electrode and stainless steel as anode and cathode, respectively (each with $78 \mathrm{~cm}^{2}$ of geometrical area). Experiments were carried out at $25^{\circ} \mathrm{C}$ by applying a current density (j) of 15 or $90 \mathrm{~mA} \mathrm{~cm}{ }^{-2}$ using a power supply to treat a $1 \mathrm{dm}^{3}$ of solution of RhB. Each one of the experiments was stopped when lower TOC values were attained. The spectrophotometric and HPLC analyses were performed for all samples.

\subsection{Chemical oxidation tests}

Solutions of oxidants were prepared by electrolyzing a solution of $\mathrm{NaCl}$ or $\mathrm{NaClO}_{4}$ at $90 \mathrm{~mA} \mathrm{~cm}{ }^{-2}$ for 480 minutes. Then the resulting solutions were dosed to synthetic wastewater containing $\mathrm{RhB}$ to assess the chemical oxidation of this organic by the oxidants produced electrolytically, in absence or in presence of light irradiation. 


\subsection{Light irradiation}

A UV lamp VL-215MC (Vilber Lourmat, $\lambda=254 \mathrm{~nm}$, intensity of $930 \mu \mathrm{W} / \mathrm{cm}^{2}$ and energy 4.43-6.20 eV (15 watts)) was used to irradiate directly the quartz cover of the electrochemical cell (in the photoelectrolysis tests) or the beakers in which the chemical oxidation was carried out (in the photochemical oxidation test).

\section{Results and discussion}

Figure 1 compares the removal of color (Fig. 1a) and COD (Fig. 1b) from wastewater containing $\mathrm{RhB}$ in $\mathrm{HClO}_{4}$ by single photolysis, electrolysis and photoelectrolysis. The changes observed in absorbance (about 5\% in Fig. 1a (black dashed curve with black squares)) in the experiments without current and UV irradiation application may be related to the disaggregation of small colloids of $\mathrm{RhB}$ caused by the stirring of the solutions. As it can be observed, single photolysis only attains a very slight change in the color (about 10\%, see Fig. 1a (blue squares)) and COD that it is negligible if compared to the results of electrolytic experiments (approximately $20 \%$ of decay, see Fig. 1b (blue squares)). The small absorbance removal observed during photolysis essays (when the solution is irradiated by UV light, without current application) can be related to the fragmentation of the chromophore group of $\mathrm{RhB}$ molecule by light irradiation [25, 34]. Meanwhile, when an increase on the applied current is attained, removal efficiency is improved, in terms of color and COD (Figures 1a and 1b) [35]. However, it is important to indicate that the irradiation of light does not contribute to improve the COD removal when current is applied (Fig. 1b (blue continuous curves with blue triangles and circles)), and it only seems to contribute to attack RhB molecule (Fig. 1a), favoring a slight decrease of absorbance respect to the tests by applying 
current. This observation can be related to the oxidation mechanism involved in the degradation process: direct and mediated processes carried out by oxidant electrogenerated in the system $[22,23,35]$. In perchlorate media, no chlorinated-oxidants production is expected and perchlorate is not a good oxidant at room temperature so, it is not expected to participate in the oxidation [22]. However, hydroxyl radicals are produced during conductive diamond electrolysis [22] and these oxidant species are transformed into more stable oxidants by combining with other hydroxyl radicals (equation 1) or oxygen (equation 2) producing hydrogen peroxide or/and ozone [10].

$$
\begin{gathered}
2 \cdot \mathrm{OH} \rightarrow \mathrm{H}_{2} \mathrm{O}_{2} \\
\mathrm{O}_{2}+2 \cdot \mathrm{OH} \rightarrow \mathrm{O}_{3}+\mathrm{H}_{2} \mathrm{O}
\end{gathered}
$$

Both ozone and hydrogen peroxide can be affected by UV light irradiation and they can regenerate the hydroxyl radical in the bulk under light irradiation (eqs. 3 and 4) $[9,16]$. This can help to explain the small improvements observed during the color decay in RhB elimination during photoelectrolysis (Fig. 1a) [34].

$$
\begin{gathered}
\mathrm{H}_{2} \mathrm{O}_{2}+\mathrm{h} v \rightarrow 2^{\bullet} \mathrm{OH} \\
\mathrm{H}_{2} \mathrm{O}_{2}+\mathrm{O}_{3}+\mathrm{h} v \rightarrow 2 \cdot \mathrm{OH}+\mathrm{O}_{2}
\end{gathered}
$$

However, the concentration of hydroxyl radicals produced seem not be enough to remove organic matter dissolved in solution (Fig. 1b) during photoelectrolysis, or actually, the irradiation seems to favor the decomposition of oxidant species [27,34], decreasing the photo-electrochemical treatment efficiency respect to the electrolysis with BDD anode.

Figure 2 compares the removal of color (Fig. 2a) and COD (Fig. 2b) from wastewater containing $\mathrm{RhB}$ in $\mathrm{NaCl}$ as supporting media by single photolysis, electrolysis and photoelectrolysis. As it can be observed, in absence of current, the removal of color (Fig. 2a, squares) and COD (Fig. 2b, squares) is almost nil. However, in chloride media 
when current is applied, the depletion of $\mathrm{RhB}$ molecule is almost instantaneous (very rapid removal of color (Fig. 2a, triangles and circles)), mainly in the electrolysis carried out at $90 \mathrm{~mA} \mathrm{~cm}^{-2}$ (Fig. 2a, circles). In all cases, the COD decreases slower than absorbance (Fig. 2b) but significantly faster than the trend observed in the electrolysis carried out in perchloric media (Figure 1b).

Main differences between the treatment of wastes containing perchloric acid or chlorides derived from the oxidants produced $[22,35]$. In chloride media, it is expected the formation of hypochlorite and hypochloric acid (eqs. 5 and 6) whose role in the treatment of a great variety of wastewaters has been tested in literature $[3,20-23,35]$. Moreover, in the case of using diamond electrodes the formation of other chloro-species such as chlorite, chlorate and perchlorate is also expected depending on the operation conditions (eqs. 7 to 9) $[21,35,36]$. Nevertheless, at the light of the obtained results (Figs. 2a and 2b), active chlorine species seem to attack very rapidly RhB molecule to form chlorinated intermediates which are slowly degraded.

$$
\begin{aligned}
& \mathrm{Cl}^{-}+\mathrm{H}_{2} \mathrm{O} \rightarrow \mathrm{HClO}+\mathrm{H}^{+}+2 \mathrm{e}^{-} \\
& \mathrm{Cl}^{-}+\cdot{ }^{-} \mathrm{OH} \rightarrow \mathrm{ClO}^{-}+\mathrm{H}^{+}+\mathrm{e}^{-} \\
& \mathrm{ClO}^{-}+\cdot{ }^{-} \mathrm{OH} \rightarrow \mathrm{ClO}_{2}^{-}+\mathrm{H}^{+}+\mathrm{e}^{-} \\
& \mathrm{ClO}_{2}^{-}+\cdot \mathrm{OH} \rightarrow \mathrm{ClO}_{3}^{-}+\mathrm{H}^{+}+\mathrm{e}^{-} \\
& \mathrm{ClO}_{3}{ }^{-}+\cdot \mathrm{OH} \rightarrow \mathrm{ClO}_{4}^{-}+\mathrm{H}^{+}+\mathrm{e}^{-}
\end{aligned}
$$

Moreover, the role of mediated oxidation seems to be more relevant at $15 \mathrm{~mA} \mathrm{~cm}^{-2}$ than at $90 \mathrm{~mA} \mathrm{~cm}^{-2}$. The high COD removal obtained in the electrolysis carried out at $15 \mathrm{~mA}$ $\mathrm{cm}^{-2}$ can be attributed to an interaction between hydroxyl radicals and $\mathrm{Cl}^{-}$to form different active chlorine species on BDD surface [20,22,35], improving the elimination of $\mathrm{RhB}$ and the by-products formed. Conversely, at $90 \mathrm{~mA} \mathrm{~cm}$, the formation of 
refractory species by chlorination may be favored, and consequently, a slower decay of organic matter is attained (Fig. 2b).

Meanwhile, the use of light irradiation does not seem to contribute COD removal of electrolytic system (Fig. 2b, see blue curves of triangles and circles), being its effect very negative in the electrolysis carried out at $15 \mathrm{~mA} \mathrm{~cm}^{-2}$. In this case, light irradiation effect on electrolysis should be focused on the decomposition of hypochlorite $[28,29]$ to form hydroxyl and chlorine radicals as the main products resulting of the light assisted degradation of hypochlorite (eqs. 10 and 11).

$$
\begin{gathered}
\mathrm{ClO}^{-}+\mathrm{h} v \rightarrow \mathrm{O}^{-\bullet}+\mathrm{Cl}^{\bullet}(10) \\
\mathrm{O}^{-\bullet}+\mathrm{H}_{2} \mathrm{O} \rightarrow \mathrm{OH}^{-}+\bullet{ }^{\bullet} \mathrm{OH}(11)
\end{gathered}
$$

Figure 3 shows the changes in the mineralization of the organic load (in terms of TOC removal) during the photolysis, electrolysis and photoelectolysis of RhB solutions in perchloric acid (Fig. 3a) and chloride media (Fig. 3b). As it was observed, mineralization rates obtained in the essays carried out in perchloric media (Fig. 3a) are consistent with absorbance and COD changes shown in Figure 1. However, in this case, light irradiation favors mineralization process, mainly during the initial stages of the process when $90 \mathrm{~mA} \mathrm{~cm}^{-2}$ were applied using BDD anode. Conversely to COD removal assumptions, the light irradiation favors the activation of oxidants to more stable species [25], favoring RhB mineralization. Probably, the measurements related to COD (Fig. 1b) were affected by the chemical reaction between dichromate with $\mathrm{H}_{2} \mathrm{O}_{2}$ produced at BDD anode, hiding significantly the effect of irradiation, when it was used.

On the other hand, mineralization results obtained during photolysis and photoelectrolysis (Fig. 3b) at $\mathrm{NaCl}$ by applying $90 \mathrm{~mA} \mathrm{~cm}$ che $^{-2}$ also consistent with absorbance and COD depletions shown in Figure 2. In this point, it is important to notice the results obtained during electrolysis and photoelectrolysis carried out at 15 
$\mathrm{mA} \mathrm{cm}{ }^{-2}$ using BDD anode. Under this condition, the electrolysis of RhB solution is very rapid, and color (Fig. 2a), COD (Fig. 2b) and even TOC (Fig. 3b) suffer a fast decrease during the first stages of the electrolysis. However, when light is irradiated to this system an abrupt decrease of mineralization rate is obtained [34]. This very low mineralization may confirm the formation of refractory species by chlorination of $\mathrm{RhB}$ molecule, if compared to color and COD removal. As stated before, the differences observed at $15 \mathrm{~mA} \mathrm{~cm}^{-2}$ in presence and absence of light irradiation may be related to the decomposition of the oxidants (mainly hypochlorite) involved in the oxidation process [28,29].

To check the role of mediated oxidation in the overall EO process and the activation of electrogenerated oxidants by means of light irradiation, several chemical oxidation essays have been carried out in absence and presence of light irradiation. Figures 4 to 6 show the COD (Fig. 4), TOC (Fig. 5) and absorbance (Fig. 6) variations, in terms of the percentage variance $(\% \Delta$ (normalized measurement $))$, during the chemical oxidation of RhB solutions with the oxidant solution produced by electrolysis of perchloric acid and sodium chloride solutions.

When the solutions of oxidants produced electrolytically are added to a wastewater containing $\mathrm{RhB}$, electrogenerated oxidants interact chemically with $\mathrm{RhB}$ and organic intermediates generated in the bulk. However, no clear influence of light irradiation can be drawn. In fact, no significant mineralization was attained in all chemical essays (Fig. 5). Taking into account that, the negative values obtained in TOC removals may be related to the accuracy of the analytical techniques. Regarding the COD removal (Fig. 4), oxidants electrogenerated in chloride (without irradiation) seem to be more effective and this can be related to the better interaction between $\mathrm{RhB}$ molecules and hypochlorite electrochemically generated. However, in both supporting media, a 
negative influence of light irradiation in COD removal can be drawn (Fig. 4, blue squares, full and clear, respectively). Regarding RhB depletion (Fig. 6), the higher the oxidant dose the higher the RhB elimination. Moreover, in this case, oxidants form during electrolysis of perchloric solutions seems to be relatively more effective (full squares, blue and black, respectively; in Fig. 6) than those obtained in chloride solutions electrolysis. It can be because in $\mathrm{HClO}_{4}$ medium, electrochemically generated oxidant species could be converted to hydroxyl radicals (such $\mathrm{H}_{2} \mathrm{O}_{2}$ or $\mathrm{O}_{3}$ (equations 3 and 4)) via irradiation; attacking the chromophore dye group, and consequently, eliminating rapidly $\mathrm{RhB}$ from solution. It is just the opposite trend observed in electrochemical essays. The diffuse effect of light irradiation may indicate that UV light irradiation has not a clear catalytic influence out of an electrolytic environment. In fact, the different behavior observed in chemical and electrochemical essays suggests that oxidants play a different role in the electrolysis of organics than that expected according to their chemical reactivity [34]. It may be due to simultaneous processes that occur in the electrochemical cell [35].

Figure 7 shows the specific efficiency $(\eta q)$, in terms of mineralization and oxidation of organic matter, of the electrolysis and photoelectrolysis in chloride and perchlorate media at different operation conditions. This parameter can be easily calculated from the slope of the semilogarithmic plot $\ln$ (concentration) vs. $q$ (eqs. 12) [37], where $\mathrm{K}_{\mathrm{L}}$ is the mass transfer coefficient, $\mathrm{A}$ is the electrode area, $\mathrm{k}_{\text {mediated }}$ the kinetic constant of mediated oxidation and $\mathrm{V}$ the reaction volume) because in a discontinuous electrochemical cell, like the one used in this study, it is directly and simultaneously related to the efficiency of the process.

$$
\ln \left(\frac{[C]_{\text {bulk }}}{[C]_{\text {bulk }}}\right)=\frac{K_{L} \cdot A+k_{\text {mediated }} \cdot V}{I} q=\eta q
$$


As it can be observed, efficiency decreases as the applied current density increases (Fig. 7). Initially, this can be explained in terms of a diffusion control of the oxidation rate. The decrease in the efficiency for the largest current density assessed, in terms of oxidation and mineralization, is smaller than expected, mainly in perchloric media, and this can be due to an additional effect of mediated electro-oxidation processes (by means of $k_{\text {mediated }}$ ). In chloride media, the efficiency for $\mathrm{RhB}$ oxidation is higher than mineralization because $\mathrm{RhB}$ decay can be attained by fragmentation of chromophore group while mineralization requires a sequence of oxidation reactions with more electric current requirements [22,35]. Regarding the UV light irradiation, its effect is very negative in the electrolysis carried out at the lowest current density, but at $90 \mathrm{~mA} \mathrm{~cm}^{-2}$ a very slight improvement of the specific efficiency is attained [34,37].

Regarding the reaction rates (Fig. 8), these can be easily calculated from the slope of the semi-logarithmic plot $\log$ (concentration) vs. time. The changes in the kinetics constants are very different of that of the specific efficiencies, in spite it is worth to consider that values of kinetic rates constant are strongly related to previous specific efficiencies. In this point it is important to notice the negative effect of light irradiation in the oxidation of $\mathrm{RhB}$ and mineralization during the electrolysis at $15 \mathrm{~mA} \mathrm{~cm}$, which can be related to the decomposition of hypochlorite electrogenerated. The effect of current density is the typical for a mass transfer controlled process with a significant contribution of mediated EO [37]: the higher the current density, the higher the production of mediated active species and hence the higher the kinetic constant. 


\section{Conclusions}

From this work the following conclusions can be drawn:

- $\mathrm{RhB}$ is rapidly degraded using electrolysis with diamond electrodes, but although media clearly influences on efficiency and rate of the processes; current density is playing an important role.

- Light irradiation effects are greater at high current densities. A relevant negative effect is attained during photoelectrolysis in chloride media and low current density. This is related to the desactivation of hypochlorite massively generated under this operating condition.

- $\quad \mathrm{RhB}$ is oxidized chemically by the oxidants electrolytically produced during the electrolysis of a chloride or perchlorate solution in the same conditions used for the electrolysis of wastewater. But, light irradiation has not a clear catalytic influence out of an electrolytic environment.

\section{Acknowledgements}

D.M.A. acknowledges the CAPES for PhD fellowship and $\mathrm{CNPq}$ for the fellowship given for "doutorado sanduiche" under "Ciências sem Fronteiras" program to develop the experimental research at the UCLM-Spain. Financial support of the Spanish government and EU through projects FEDER 2007-2013 PP201010 (Planta Piloto de Estación de Estación de Regeneración de Aguas Depuradas) and CTM2013-5612-R are gratefully acknowledged. 


\section{References}

[1] E. Brillas, C.A. Martínez-Huitle, Decontamination of wastewaters containing synthetic organic dyes by electrochemical methods. An updated review, Appl. Catal. B: Environ. 166-167(2015) 603-643.

[2] C. Saez, M. Panizza, M.A. Rodrigo, G. Cerisola, Electrochemical incineration of dyes using a boron-doped Diamond anode, J. Chem. Technol. Biot. 82 (2007) 575-581.

[3] A.M.S. Solano, C.K.C. Araújo, J.V. Melo, J.M. Peralta-Hernandez, D. R. da Silva, C.A. Martinez-Huitle, Decontamination of real textile industrial effluent by strong oxidation species electrogenerated on diamond electrode: Viability and disadvantages of this electrochemical technology. Appl. Catal. B: Environ. 130-131 (2013) 112-120.

[4] C.H. Yang, C.C. Lee, T.C. Wen, Hypochlorite generation on Ru-Pt binary oxide for treatment of dye waswater. J. Appl. Electrochem. 30 (2000) 1043-1051.

[5] S. Garcia-Segura, S. Dosta, J.M. Guilemany, E. Brillas, Solar photoelectrocatalytic degradation of Acid Orange 7 azo dye using a highly stable $\mathrm{TiO}_{2}$ photoanode synthesized by atmospheric plasma spray, Appl. Catal. B: Environ. 132-133 (2013) 142150.

[6] A. M. Polcaro, A. Vacca, M. Mascia, S. Palmas, J. R. Ruiz, Electrochemical treatment of waters with BDD anodes: kinetics of the reactions involving chlorides. J. Appl. Electrochem. 39 (2009) 2083-2092.

[7] B. A. Wols, C. H. M. Hofman-Caris, Review of photochemical reaction constants of organic micropollutants required for UV advanced oxidation processes in water. Water Res., 46 (2012) 2815-2827.

[8] Y. J. Shih, K. H. Chen, Y. H. Huang, Mineralization of organic acids by the photoelectrochemical process in the presence of chloride ions. J. Taiwan Institute Chem. Eng. 45 (2014) 962-966. 
[9] M. A. Oturan, J.-J. Aaron, Advanced oxidation processes in water/wastewater treatment: principles and applications. A review. Crit. Rev. Env. Sci. Technol. 44 (2014) 2577-2641.

[10] I. Sirés, E. Brillas, M.A. Oturan, M.A. Rodrigo, M. Panizza, Electrochemical advanced oxidation processes: today and tomorrow. A review. Environ. Sci. Pollut. Res. $21(2014) 8336-8367$.

[11] Ch. Comninellis, G. Chen (Eds.), Electrochemistry for the Environment Springer, 2010.

[12] J.H.B. Rocha, A.M.S. Solano, N.S. Fernades, D.R. da Silva, J.M. PeraltaHernandez, C.A. Martínez-Huitle, Electrochemical Degradation of Remazol Red BR and Novacron Blue C-D Dyes Using Diamond Electrode. Electrocatalysis 3 (2012) 112.

[13] M. Panizza, G. Cerisola, Direct and mediated anodic oxidation of organic pollutants, Chem. Rev. 109 (2009) 6541-6569.

[14] C.A. Martinez-Huitle, S. Ferro, Electrochemical oxidation of organic pollutants for the wastewater treatment: direct and indirect processes. Chem. Soc. Rev. 35 (2006) $1324-1340$

[15] B. Marselli, J. Garcia-Gomez, P.A. Michaud, M.A. Rodrigo, C. Comninellis, Electrogeneration of hydroxyl radicals on boron-doped diamond electrodes. J. Electrochem. Soc. 150 (2003) D79-D83.

[16] M.A. Oturan, , N. Oturan, C. Lahitte, S. Trevin, Production of hydroxyl radicals by electrochemically assisted Fenton's reagent - Application to the mineralization of an organic micropollutant, pentachlorophenol. J. Electroanal. Chem. 507 (2001) 96-102. 
[17] O. Scialdone, Electrochemical oxidation of organic pollutants in water at metal oxide electrodes: A simple theoretical model including direct and indirect oxidation processes at the anodic surface. Electrochim. Acta, 54 (2009) 6140-6147.

[18] A. Vacca, M. Mascia, S. Palmas, A. Da Pozzo, Electrochemical treatment of water containing chlorides under non-ideal flow conditions with BDD anodes. J. Appl. Electrochem. 41 (2011) 1087-1097.

[19] F. Bonfatti, S. Ferro, F. Lavezzo, M. Malacarne, G. Lodi, A. De Battisti, Electrochemical inceneration of glucose as a midel organic substrate II. Role of active chlorine mediation. J. Electrochem. Soc. 172 (2000) 592-596.

[20] J. M. Aquino, M. A. Rodrigo, R. C. Rocha-Filho, C. Saez, P. Canizares, Influence of the supporting electrolyte on the electrolyses of dyes with conductive-diamond anodes. Chem. Eng. J. 184 (2012) 221-227.

[21] M. Bergmann, J. Rollin, T. Iourtchouk, The occurrence of perchlorate during drinking water electrolysis using BDD anodes. Electrochim. Acta 54 (2009) 2102-2107. [22] A. Uranga-Flores,; C. de la Rosa-Júarez, S. Gutierrez-Granados, D. C. Moura,; C. A. Martínez-Huitle, J. M. Peralta-Hernández, Electrochemical promotion of strong oxidants to degrade Acid Red 211: Effect of supporting electrolytes. J. Electroanal. Chem., 738 (2015) 84-91.

[23] A. Sánchez-Carretero, C. Sáez, P. Cañizares, M. A. Rodrigo, Electrochemical production of perchlorates using conductive diamond electrolyses. Chem. Eng. J. 166 (2011) 710-714.

[24] D. C. Moura, C. K. C. Araújo, C. L. P. S. Zanta, R. Salazar, C. A. Martínez-Huitle, Active chlorine species electrogenerated on $\mathrm{Ti} / \mathrm{Ru}_{0.3} \mathrm{Ti}_{0.7} \mathrm{O}_{2}$ surface: Electrochemical behavior, concentration determination and their application. J. Electroanal. Chem. 731 (2014) 145-152. 
[25] G. Hurwitz, P. Pornwongthong, S. Mahendra, E. M. V. Hoek, Degradation of phenol by synergistic chlorine-enhanced photo-assisted electrochemical oxidation. Chem. Eng. J. 240 (2014) 235-243.

[26] R. Pelegrini, J. Reyes, N. Durán, P. P. Zamora, A. R. de Andrade, Photoelectrochemical degradation of lignin. J. Appl. Electrochem. 30 (2000) 953-958.

[27] H. Bergmann, T. Iourtchouk, K. Schöps, K. Bouzek, New UV irradiation and direct electrolysis-promising methods for water disinfection. Chem. Eng. J. 85 (2002) 111117.

[28] B. G. Oliver, J. H. Carey, Photochemical production of chlorinated organics in aqueous solutions containing chlorine. Environ. Sci. Technol. 11 (1977) 893-895.

[29] P. Y. Chan, M. G. El-Din, J. R. Bolton, A solar-driven UV/Chlorine advanced oxidation process. Water Res. 46 (2012) 5672-5682.

[30] R. Hiller, S. J. Putterman, B. P. Barber, Spectrum of synchronous picosecond sonoluminescence. Phys. Rev. Lett. 69 (1992) 1182-1184.

[31] D. J. Flannigan, K. S. Suslick, Plasma formation and temperature measurement during single-bubble cavitation. Nature 434 (2005) 52-55.

[32] J. Rooze, E. V. Rebrov, J. C. Schouten, J. T. Keurentjes, Dissolved gas and ultrasonic cavitation - a review. Ultrason. Sonochem. 20 (2013) 1-11.

[32] C. Miller, H. Yu, T. Waite, Degradation of rhodamine B during visible light photocatalysis employing $\mathrm{Ag} @ \mathrm{AgCl}$ embedded on reduced graphene oxide. Coll. Surf. A - Physicochem. Eng. Aspects 435 (2013) 147-153.

[33] M. Hou, L. Liao, W. Zhang, X. Tang, H. Wan, G. Yin, Degradation of rhodamine B by $\mathrm{Fe}(0)$-based Fenton process with $\mathrm{H}_{2} \mathrm{O}_{2}$. Chemosphere 83 (2011) 1279-1283. 
[34] F. L. Souza, C. Saez, P. Canizares, A. J. Motheo, M. A. Rodrigo, Coupling photo and sono technologies to improve efficiencies in conductive diamond electrochemical oxidation, Appl. Catal. B: Environ. 144 (2014) 121-128.

[35] D. Medeiros de Araújo, C. Sáez, C. A. Martínez-Huitle, P. Cañizares, M.A. Rodrigo, Influence of mediated processes on the removal of Rhodamine with conductive-diamond electrochemical oxidation. Appl. Catal. B: Environ. 166-167 (2015) 454-459.

[36] S. Garcia-Segura, E. V. dos Santos, C. A. Martínez-Huitle, Role of $\mathrm{sp}^{3} / \mathrm{sp}^{2}$ ratio on the electrocatalytic properties of boron-doped diamond electrodes: A mini review. Electrochem. Comm. 59 (2015) 52-55.

[37] F. de Souza, C. Sáez, P. Cañizares, A. Motheo, M. Rodrigo, Electrochemical removal of dimethyl phthalate with diamond anodes. J. Chem. Technol. Biotechnol. 89 (2014) 282-289. 


\section{Figure Captions.}

Figure 1. (a) Color and (b) COD removal progress during the photolysis, electrolysis and photoelectrolysis of solutions containing $\mathrm{RhB}$ in $\mathrm{HClO}_{4}$ by applying $\mathrm{j}=0 \mathrm{~mA} \mathrm{~cm}{ }^{-2}$

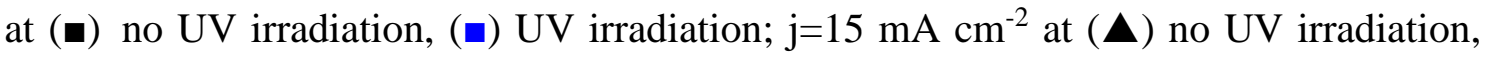
(A) UV irradiation and j=90 $\mathrm{mA} \mathrm{cm}^{-2}$ at ( no UV irradiation, ( ) UV irradiation.

Figure 2. (a) Color and (b) COD removal progress during the photolysis, electrolysis and photoelectrolysis of solutions containing $\mathrm{RhB}$ in $\mathrm{NaCl}$ by applying $\mathrm{j}=0 \mathrm{~mA} \mathrm{~cm}{ }^{-2}$ at

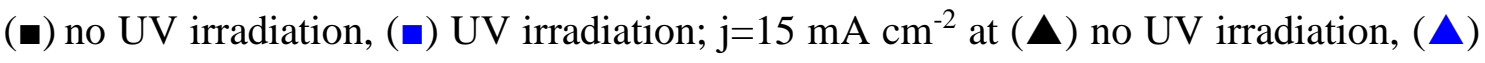
UV irradiation and $\mathrm{j}=90 \mathrm{~mA} \mathrm{~cm}^{-2}$ at ( ono UV irradiation, ( ) $\mathrm{UV}$ irradiation.

Figure 3. Mineralization behaviour during the photolysis, electrolysis and photoelectrolysis of solutions containing $\mathrm{RhB}$ in $\mathrm{HClO}_{4}$ (a) and $\mathrm{NaCl}$ (b) under different conditions: $\mathrm{j}=0 \mathrm{~mA} \mathrm{~cm}{ }^{-2}$ at (a) no $\mathrm{UV}$ irradiation, (a) $\mathrm{UV}$ irradiation; $\mathrm{j}=15 \mathrm{~mA} \mathrm{~cm}^{-2}$ at

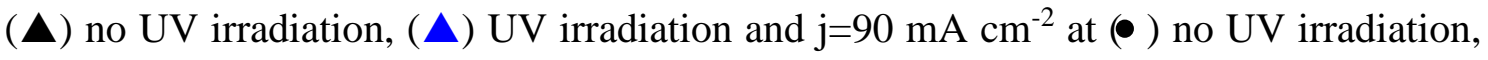
(•) UV irradiation.

Figure 4. Variation in the percentage of normalized COD as a function of oxidant dose in solution produced by the electrolyses of $\mathrm{HClO}_{4}$ and $\mathrm{NaCl}$, during the chemical oxidation of $\mathrm{RhB}$ : $\mathrm{HClO}_{4}$ : (घ) no UV irradiation, ( $\left.\mathbf{a}\right) \mathrm{UV}$ irradiation. $\mathrm{NaCl}$ : (ㅁ) no UV irradiation, ( ) UV irradiation.

Figure 5. Variation in the percentage of normalized TOC as a function of oxidant dose in solution produced by the electrolyses of $\mathrm{HClO}_{4}$ and $\mathrm{NaCl}$, during the chemical oxidation of $\mathrm{RhB}: \mathrm{HClO}_{4}$ : (घ) no UV irradiation, (घ) UV irradiation. $\mathrm{NaCl}$ (ם) no UV irradiation, (ㅁ) UV irradiation.

Figure 6. Variation on the percentage of normalized $\mathrm{RhB}$ concentration as a function of oxidant dose in solution produced by the electrolyses of $\mathrm{HClO}_{4}$ and $\mathrm{NaCl}$, during the 


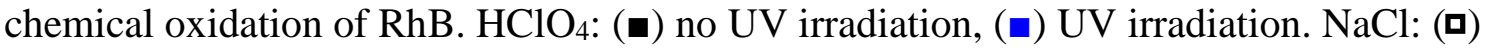
no UV irradiation, ( a UV irradiation.

Figure 7. Specific efficiency $(\eta q)$ in the oxidation and mineralization of RhB solutions by electrolysis and photoelectrolysis in $\mathrm{NaCl}$ and $\mathrm{HClO}_{4}$ at different operation

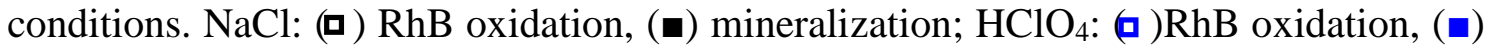
mineralization.

Figure 8. Kinetic constants in the oxidation and mineralization of RhB solutions by electrolysis and photoelectrolysis in $\mathrm{NaCl}$ and $\mathrm{HClO}_{4}$ at different operation conditions.

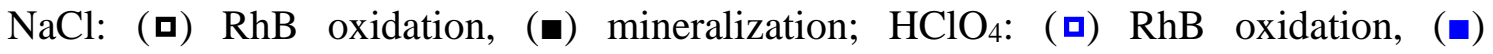
mineralization. 

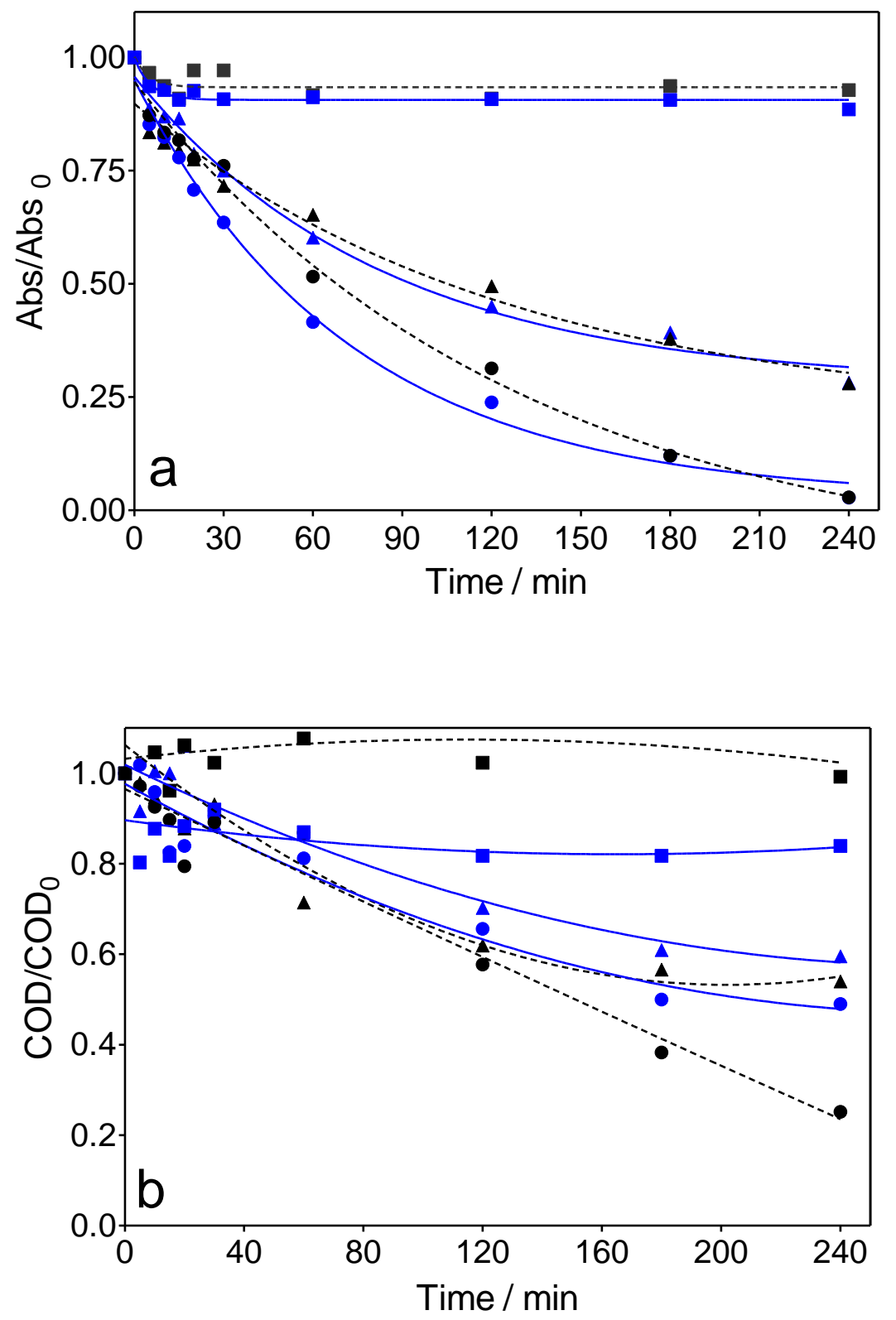

Figure 1 

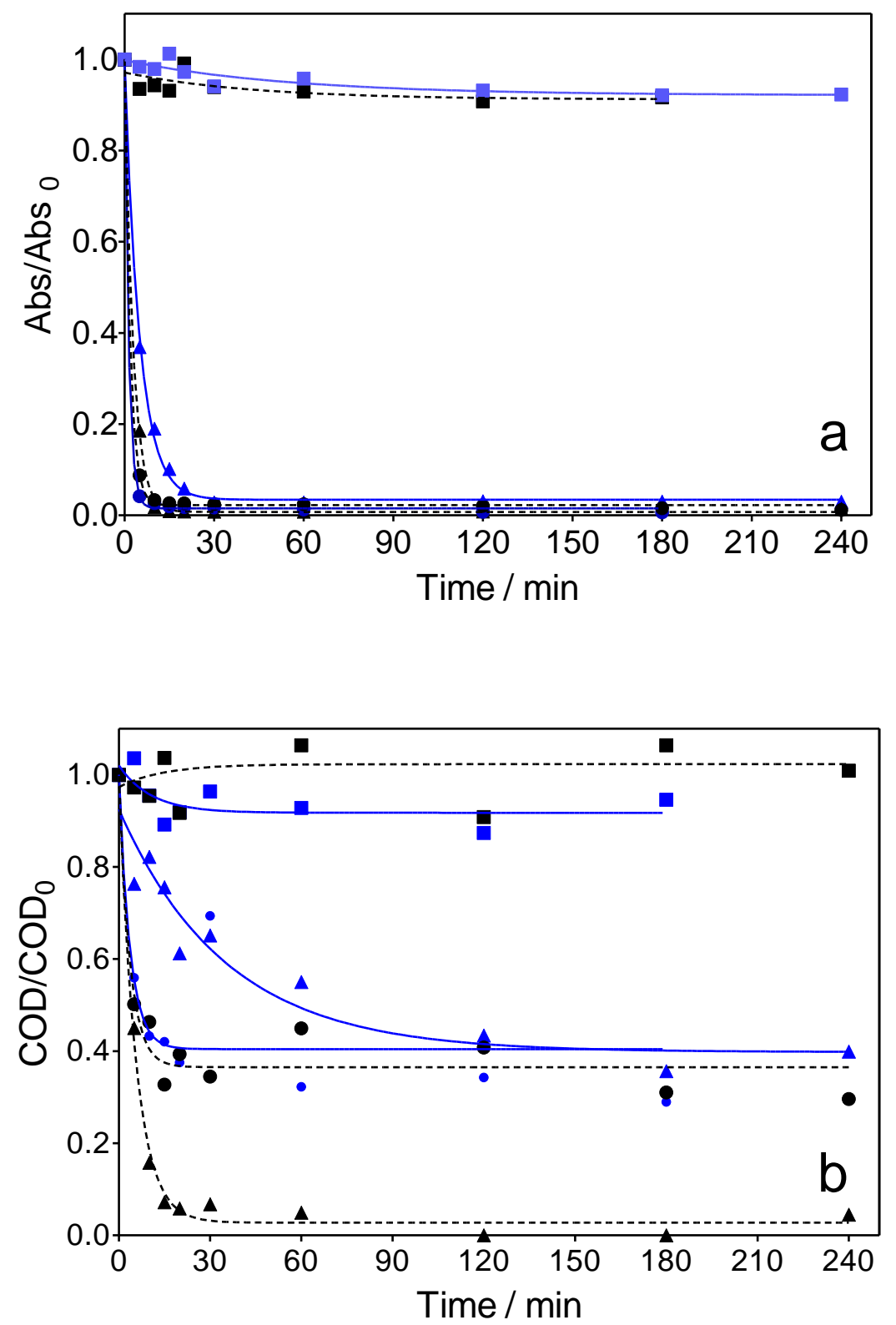

Figure 2 

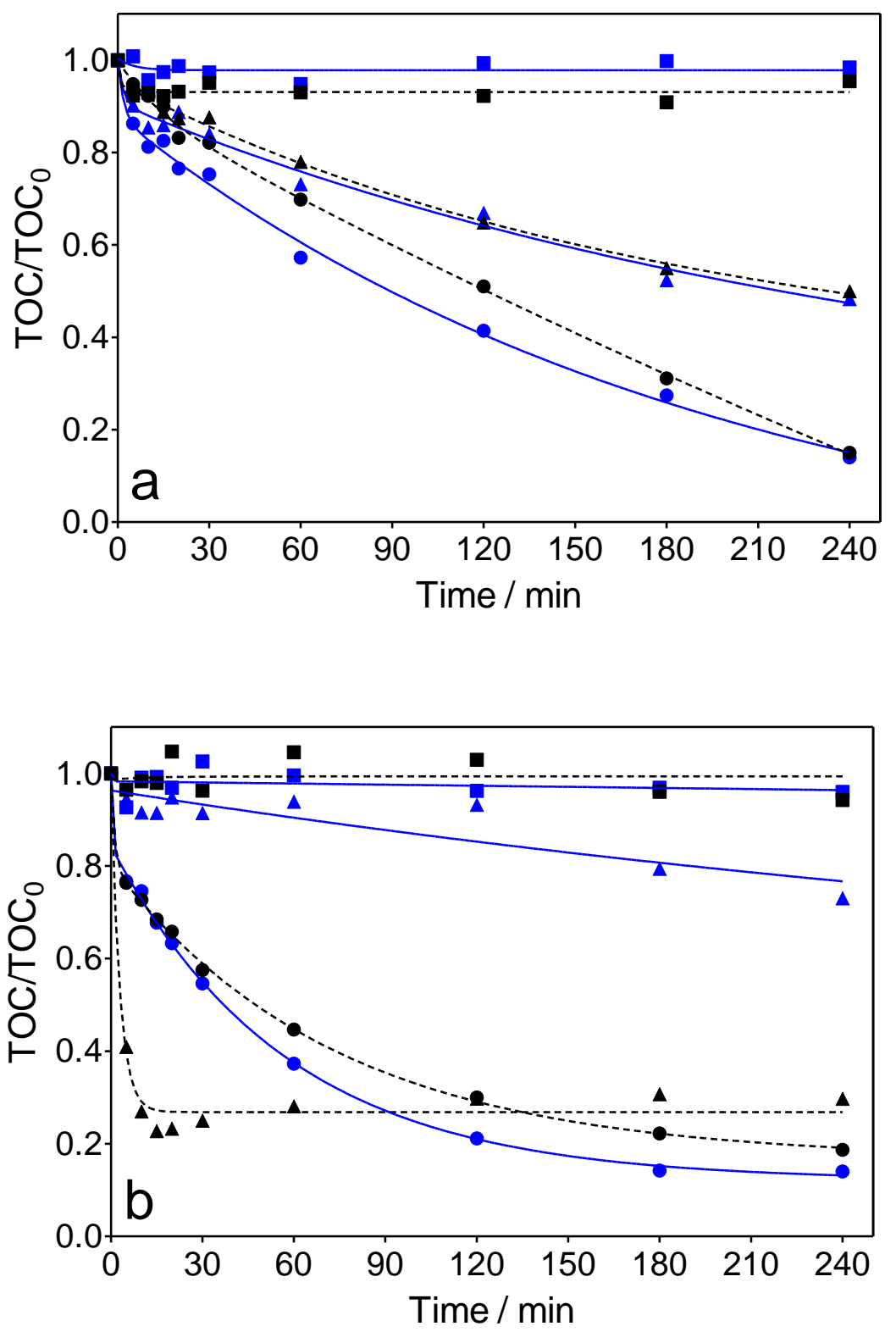

Figure 3 


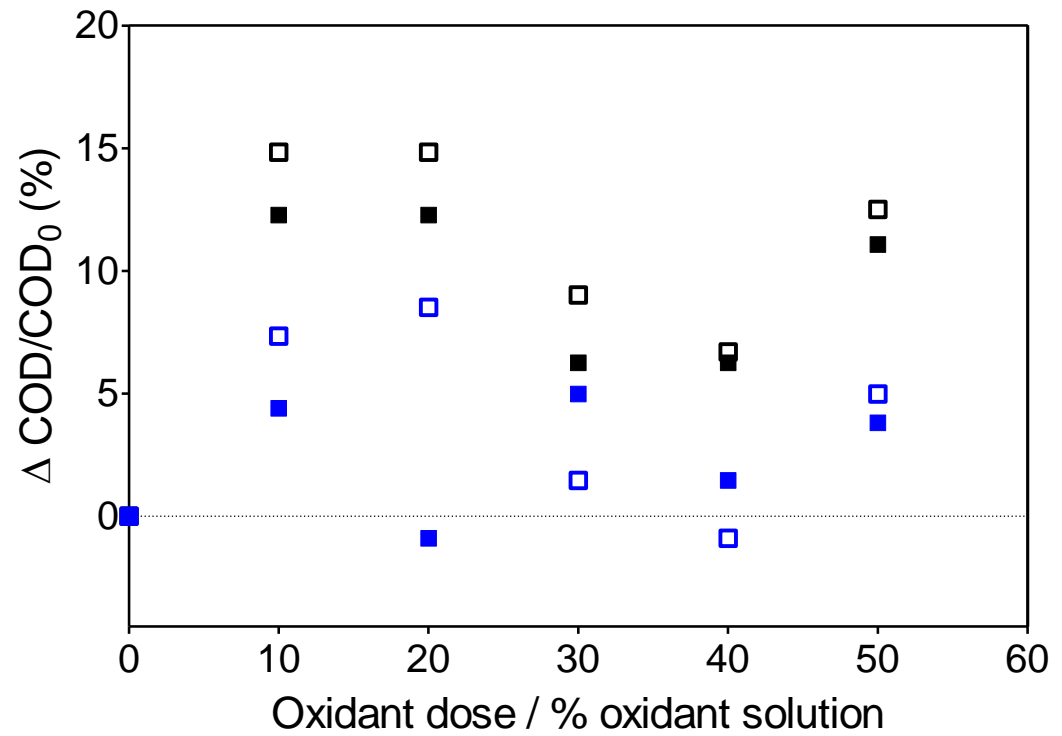

Figure 4 


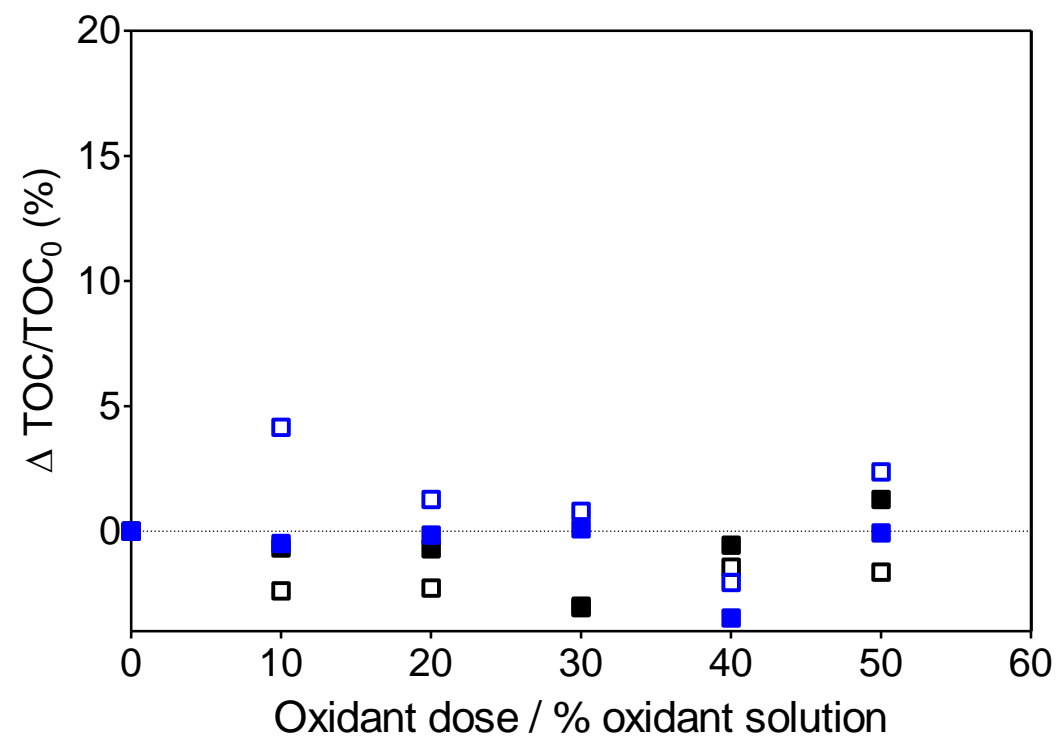

Figure 5 


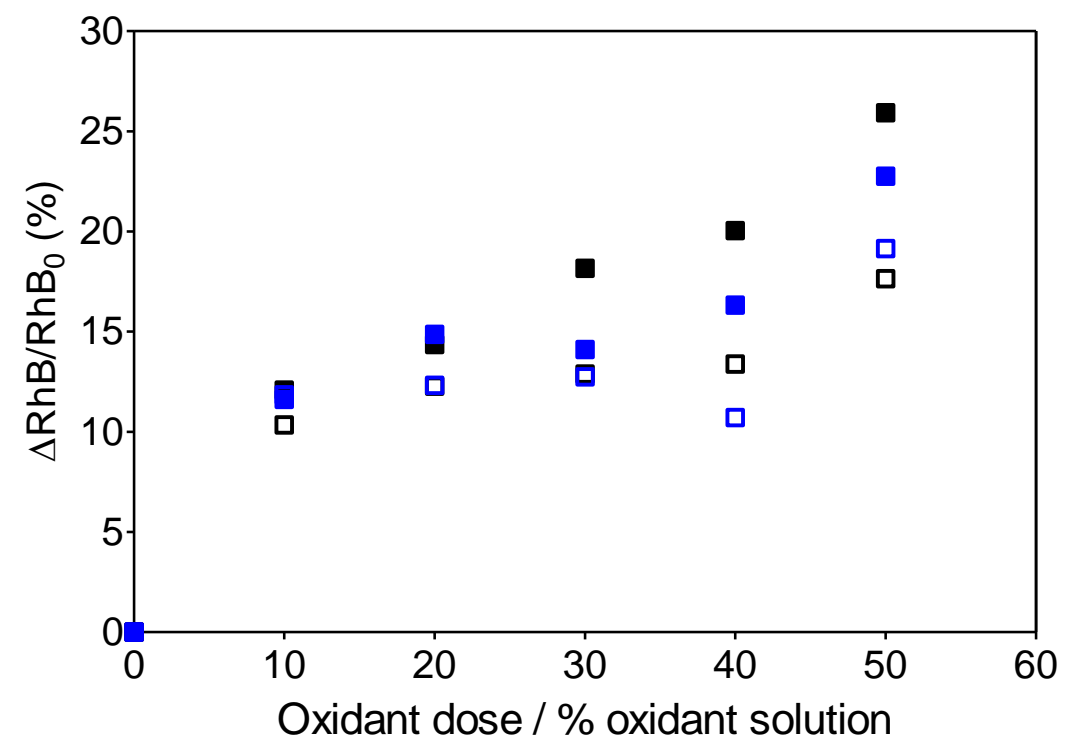

Figure 6 


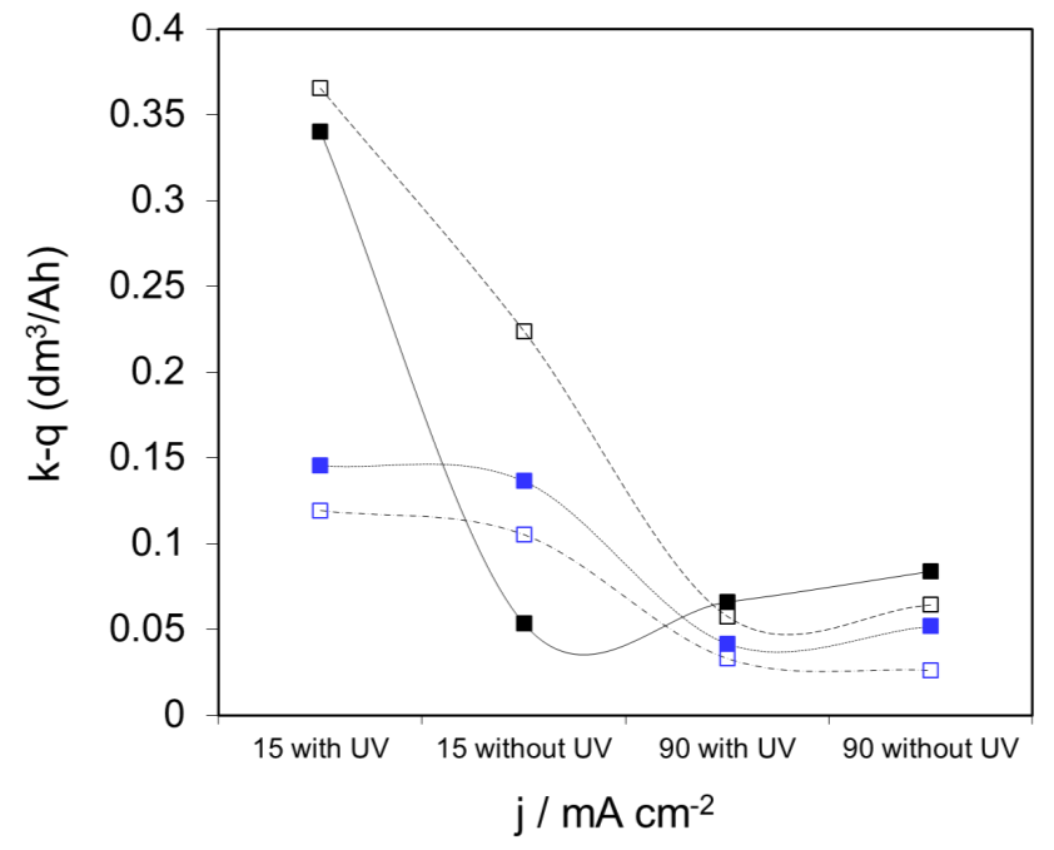

Figure 7 


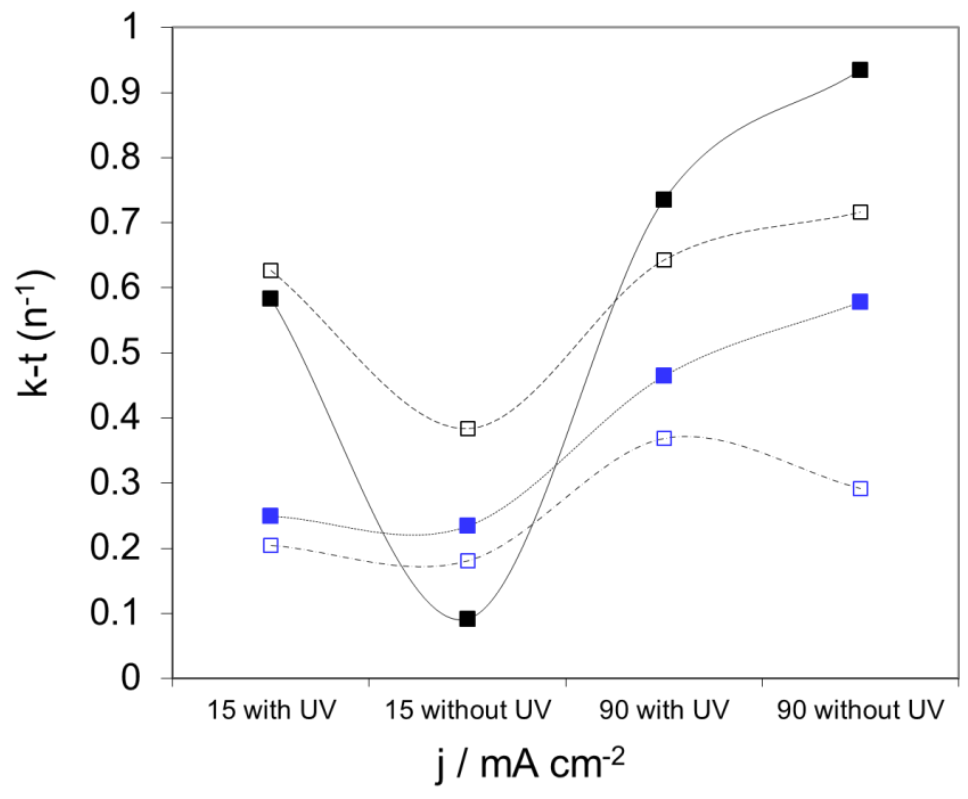

Figure 8 